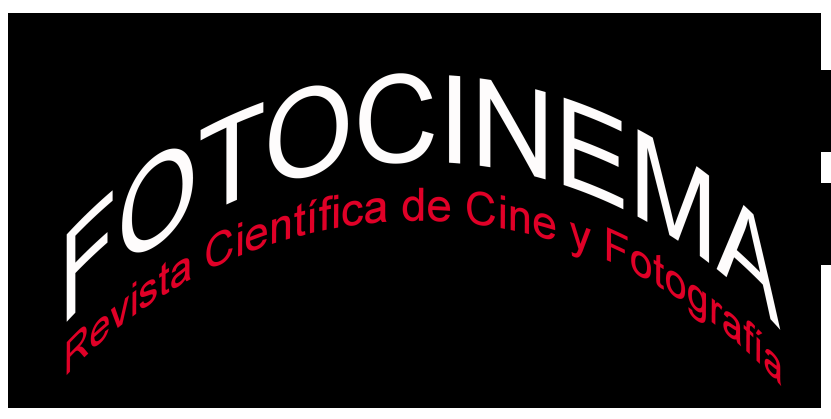

\title{
PorNO FUTURE: ESTÉTICA DEL TOTALITARISMO EN LA BILOGÍA LATEX Y SHOCK, DE MICHAEL NINN
}

\section{PorNO FUTURE: AESTHETICS OF TOTALITARIANISM IN MICHAEL NINN'S DUOLOGY LATEX AND SHOCK}

\section{Resumen:}

Durante los años 90, antes de los cambios definitivos que en la industria y la distribución de la pornografía introdujo la era digital, algunos directores cobraron un marcado protagonismo debido a su voluntad de elevar el género a nuevos estándares artísticos. En el porno heterosexual estadounidense destacó sobradamente Michael Ninn, quien, con su bilogía Latex (1995) y Shock (1996), se internó en lenguajes técnicos poco explorados, sirviendo al mismo tiempo una estética particular sobre el sexo y la dominación en los regímenes totalitarios, que además actúan como eje argumental de ambas películas. Este artículo explora sus aportaciones en este último plano, recorriendo los dos filmes mediante un breve análisis sobre la fascinación histórica por la relación entre sumisión y erotismo, las conexiones cinéfilas y las claves técnicas de las dos películas, y la exclusiva aplicación de estos conceptos a la tradicional exhibición del acto sexual con que Ninn las pergeñó.

\section{David Fuentefría Rodríguez \\ Universidad de La Laguna, España dfuentef@ull.es}

\begin{abstract}
:
During the 1990s, before the definitive changes introduced by the digital age, in industry and the distribution of pornography, some directors gained a marked role due to their willingness to elevate the genre to new artistic standards. The heterosexual american porn amply highlighted Michael Ninn, who, with his duology Latex (1995) and Shock (1996), was interned in unexplored technical languages, serving at the same time a particular aesthetic about sex and domination in totalitarian regimes, which also act as plot axis of both films. This article explores his contributions in this last plane, traveling the two films by a brief analysis of the historical fascination with the relationship between submission and eroticism, the active connections and technical keys of the two films, and the exclusive application of these concepts to the traditional display of the sexual act with that Ninn engineered them.
\end{abstract}

Palabras clave: pornografía; totalitarismo; Michael Ninn; estética.

Keywords: Pornography; totalitarianism; Michael Ninn; Aesthetics. 
Cómo citar: Fuentefría Rodríguez, D. (2017). "PorNo Future: estética del totalitarismo en la bilogía "Latex" y "Shock", de Michael Ninn". Fotocinema. Revista científica de cine y fotografía, $\mathrm{n}^{\mathrm{o}} 15$, pp. 179-201. Disponible: http://www.revistafotocinema.com/

\section{Introducción: los pornosoñadores}

Si la excitación morbosa de la sexualidad, su obscenidad intencional, es lo que define y diferencia pornografía de erotismo, no resulta arduo depositar en la subjetividad del observador la gradación y el alcance del concepto de morbo. A poco que se revise el devenir del denominado cine pornográfico, resulta un placer no sensual indagar en los códigos temporales que han ido apuntalando la exhibición estética de la impudicia, explicitada siempre, pese a sus múltiples variaciones, en calidad de fractura o de separación abrupta y voluntaria con las convenciones sociales y/o religiosas en materia sexual. Desde los primeros filmes mudos, realizados para solaz de clases acomodadas, en los que los actores masculinos aparecían ocultos tras barbas falsas, a la revolución hippie de los años 60, cuando el semen se consagra como indómito viajero hacia lugares del cuerpo distintos al designado por Dios, no han faltado tentativas por describir la curva exacta que difuminase, con su propio sentido del equilibrio, las barreras morales entre lo público y lo privado. Gerard Damiano, director de Garganta profunda (Deep Throat, 1972), soñó, a tenor de la repercusión extramuros de su obra, con una generalización posible de la exhibición carnal fuera de los circuitos marginales, testigo que ya habían tomado algunas manifestaciones del cine independiente al insertar escenas de sexo real dentro de propuestas como Soy curiosa (Jag är nyfiken, Vilgot Sjöman, 1967), o, un poco más tarde, Sweet Movie (Dušan Majavejev, 1974), recordadas en Europa por sus polémicas singularidades.

Esta tendencia, que también lega apuntes en Asia, desde el clasicismo de Nagisha Oshima (El imperio de los sentidos, Ai no korîda, 1976) a la autosuficiencia de Apichatpong Weerasetakhul (Blissfully yous, 2002), ha ido integrando además, en proyectos puntuales con escenas explícitas, a 
actores convencionales de reconocible trayectoria, como Maruschka Detmers, pionera en practicar una felación no simulada en El diablo en el cuerpo (Le diable au corps, Marco Bellocchio, 1986); Chloe Sevigny, en la muy outsider The Brown Bunny (Vincent Gallo, 2003), o la pareja compuesta por Margo Stilley y Kieran O’Brien en 9 Songs (Michael Winterbottom, 2004), por citar solo unos pocos ejemplos.

Pero, fuera de tanteos experimentales, el dictamen social, y las inercias manufactureras de la industria "corriente", la que ayer anegaba de películas los reservados de los videoclubes como hace hoy con servidores y redes, han sido los principales responsables de que la pornografía siga conservándose, cuando no languideciendo, por lo general, en sus límites y recoletos pese a sus últimos cambios de ritmo (o precisamente por ellos, como veremos en breve).

En los años 80, y durante casi toda la década de los 90, el porno heterosexual made in USA, en el que continuaremos centrándonos por el influjo y liderazgo de su producción, se asentaba (como buena parte del europeo), en un patrón estético a caballo entre lo moderno y lo kitsch; en ensueños triviales rociados con laca, brillantina y hot fashion; en charoles estrafalarios y atmósferas coloridas, comunicantes con la Cultura VHS, y en permanentes apuntes paródicos -cuando no en versiones directas- tanto de los géneros canónicos del cine, y de sus éxitos principales, como de las fantasías paramétricas del morbo straight, consideradas por el mundo occidental y denostadas por la tradición católica. David Foster Wallace, en su colección de ensayos referenciales "Hablemos de langostas", describió magistralmente el trasfondo falsamente alternativo de este particular "mundo al margen":

Una gran parte de la industria del cine para adultos de hoy día parece una parodia torpe de Hollywood y del conjunto del país. Las actrices más famosas son caricaturas de tebeo del atractivo sexual. Las prótesis de pechos y las nalgas implantadas y (no es broma) los pómulos artificiales no son nada más que subrayados de una mentalidad que potencia las liposucciones masivas y la industria del colágeno (...). Por no mencionar el hecho de que la industria del cine para adultos coge muchas de las deformidades por las que Hollywood es 
famoso -la vanidad, la vulgaridad, el mercantilismo rancio- y no solamente las vuelve explícitas y grotescas, sino que parece regodearse en esa naturaleza (Foster, 2009, p.42).

Ahora bien; si, objetivamente, y por las razones descritas, la trayectoria de este género correlativo al nacimiento mismo del cine tendía hasta este instante a presuponerse ayuno de contenido intelectualizable, el cambio capital en el modo de producción y distribución de la pornografía conexo a la progresión de los avances tecnológicos ha llevado nada menos que a reconocer, hogaño, no ya el appeal creativo de algunos casos particulares, sino, ante todo, el innegable vigor técnico general de aquellas cintas precedentes. En este sentido, los especialistas recuerdan que

Cuando las producciones X se rodaban en 35 milímetros, se tenía en cuenta la dirección, el guion, la fotografía, el montaje, la decoración, el vestuario y las interpretaciones. También era fundamental la carga erótica de la historia y la morbosidad de las situaciones. Desde la aparición del vídeo y la hegemonía del subgénero gonzo, cada vez fue más difícil encontrar películas que se pudiesen valorar con criterios cinematográficos. En la era internet solo es posible analizar el porno como reflejo de las perversiones o aberraciones de la sociedad. Y el diagnóstico es aterrador (Soler, 2017).

\section{Los directores artísticos. Michael Ninn. La estética de la dominación}

Por todo ello resulta interesante situar objeto y estudio, precisamente, en este período predigital, y postrero a la edad dorada del Porno Chic encabezado por Damiano, lejos ya, por tanto, de la mirada de las celebridades y los medios mainstream de la época. Salvo por una mayor (y más visible) concienciación en la industria sobre el efecto devastador del VIH, los años 90 no terminaron de desentenderse del sopor que adocenaba planteamientos y temáticas en un continuismo laxo respecto a la década anterior, por lo que no era complicado entrever, cuando la había, la querencia de algunos directores por oxigenar sus productos con cierto canon de innovación, casi siempre dentro de una vis perfeccionista. Así lo entiende Purcell (2012, p. 194), 
cuando afirma: "Many 1990s directors equated class with artistry. They worked to imitate hit MTV videos and bold Hollywood directors". Mas el liderazgo de esta corriente, en el que la autora incluía también a Antonio Passolini, es claramente bicéfalo y vino capitaneado, principalmente, por la paisajística arquitectónica y la espectacularidad classy de Andrew Blake, y por el futurismo tecnológico, y el expedito amor por las tendencias, de Michael Ninn.

Procedente, como es sabido, del mundo de las agencias de Publicidad, la filmografía de Ninn acusa un prurito experimental muy ilustrativo de su talante que, entre su debut, Two Sisters (1992), y sus incursiones más singulares, como la infortunada animación digital 2 Funky 4 You (2002), abriga su segmento más profesional dentro de la década citada, con las dos partes de Sex (1994 y 1995), y la bilogía clave para este artículo: Latex (1995) y Shock (1996). Amparado por la potente disposición presupuestaria de la productora VCA, a priori no podía partirse de una premisa argumental más atractiva (incluso para no pornógrafos), ni más obsequiosa, al tiempo, con los fundamentos del género: en un Estado futuro de corte totalitario, la existencia de Malcolm Stevens (John Dough), nacido con el don de percibir y visionar las fantasías sexuales más profundas de sus semejantes, supone una auténtica amenaza para el sistema, que intentará reiteradamente retenerlo y confinar su poder tanto física como psíquicamente. Durante el desarrollo de ambas cintas, asistimos a diversas reflexiones visuales y dialécticas, servidas, entre otros personajes menores, por el antagonismo del Líder de esta distopía (Jonathan Morgan), y sobre todo de la psiquiatra que trata a Stevens, la doctora Lillian Mangrove (Tyffany Million).

Desde un prisma integrador, en términos antropológicos, no es difícil intuir que estamos a punto de adentrarnos en un terreno en el que, como indicaran Hernández y Crespo (2013), "la vulgar asimilación del porno a la satisfacción masturbatoria olvida las diversas sensaciones que el género propicia”, por cuanto, en contadas producciones como las que van a ocuparnos, hablaríamos no solo "de un espacio de goce y estímulo libidinal", sino también, en abierta metáfora, "del comportamiento y la condición humana”. 
En honor a la verdad, que ambas películas vinieran envueltas en celofanes tecnológicos, y en su privativa vocación de ruptura, no quiere decir que se sustraigan a los anacolutos comunes al género. Aun así, conviene revisar su impacto estético en este texto, por cuanto la plasmación de las fantasías que en ellas aparecen obliga a regresar, por unos instantes, a la apelación inicial sobre la subjetividad del concepto de morbo. Un morbo, como veremos, relacionado para Ninn, necesariamente, con la estilización (no precisamente original, pero tal vez la mejor acicalada de su tiempo) del cesarismo tiránico fuste de las autocracias más crudas del siglo XX.

Vayamos por partes: si, como dice Zavala (2014), "el cuerpo remite a lo sexual, y cada cultura humaniza la carnalidad, por un lado, al mismo tiempo que utiliza el cuerpo como representante de una ética y una estética”, en Latex y Shock hallamos sexo visibilizado siempre en unas apariencias externas insólitas, que tienden a armonizar lo cyberpunk y lo manifiestamente nazi, aunque contextualizadas, situacionalmente, en un campo ideológico más cercano al estalinismo.

No es un contrasentido:

La fotografía y el cine como cómplices de unas expresiones estéticas en una sociedad ciberespacial, entretejen un mundo de significaciones entre la técnica, el cuerpo y la mirada, logrando reorganizar los lenguajes afectivos y eróticos desde el placer y el goce del espectador en virtud de encontrar la satisfacción visual y perceptual en figuras, formas y modalidades del erotismo estetizadas (Gonzáles, 2012).

Ya era así, como vemos, en el marco previo a esa sociedad ciberespacial a la que se refiere el autor. Por tanto, para buscar los orígenes de la fascinación, o más concretamente, del peculiar lenguaje de la sumisión sexual dentro de una estética tan particular como la de los antiguos Estados totalitarios, es de recibo sintetizar, ahora, conceptos sobre el móvil, no tan sorprendente, de la relación entre estos elementos.

En un plano inicial, damos la razón a Ruiz-Tagle (2013, p. 179) cuando afirma que quienes participan del BDSM, e incluso del posporno, hallan 
perspectivas conexas al creerse "dueños de una sexualidad radical, que a fuerza de creatividad podría ayudarlos a liberarse del yugo de identidades anquilosadas y destinos inapelables”. A partir de ahí, es en el terreno de la fantasía sexual donde la cuestión encuentra correlaciones con el estalinismo y el nazismo, toda vez que, por un lado:

En la época de Stalin la frigidez femenina era un fenómeno masivo. Conviene recordar a tal fin que la mejor manifestación de feminidad quedaba inmediatamente catalogada como decadente y burguesa. Si una mujer usaba lápiz de labios o se atrevía a lucir prendas abigarradas, ya podía estar segura de sufrir las agresiones verbales de los transeúntes y de tener que presentarse en una reunión de las juventudes comunistas o del sindicato, donde la censuraban (Corazón, 2013).

$\mathrm{Y}$, en el extremo diametralmente opuesto, entran en juego las aseveraciones de Pagés y Rubí, cuando indican que:

El arte sigue contribuyendo a una simbolización acabada de las prácticas sexuales más arraigadas: la agresividad, la posesión, la delimitación de los cuerpos, el placer en vinculación a la tortura, la propiedad y el sometimiento. Es allí que el nazismo se encarna como el hecho perfecto para representar un paraíso de lo erótico (Pagés \& Rubí, 2012, p. 33).

Pero la aportación definitiva sobre la verdadera retórica, y diríase que incluso sobre buena parte de la logística, de la relación entre porno y dictadura viene, a nuestro juicio, de la mano de Susan Sontag, quien halla claves:

en la predilección de los dirigentes fascistas por las metáforas sexuales. Como Nietzsche y Wagner, Hitler consideraba el mando como un dominio sexual de las masas femeninas, como violación (la expresión de las muchedumbres en 'El triunfo de la Voluntad' es de éxtasis; el líder provoca un orgasmo a las masas). Los movimientos izquierdistas han tendido a ser unisex y asexuales en sus imágenes. Los movimientos de derecha, por muy puritanas y represivas que sean las realidades que introducen, tienen una superficie erótica. Ciertamente el nazismo es más sexy que el comunismo (lo que no va en crédito de los nazis sino que, antes bien, muestra algo de la naturaleza y los límites de la imaginación sexual) (Sontag, 2011, p. 96). 
De ahí que Latex y Shock conjuguen, acaso en aras de una voluntad de epatar mayor que la de levantar pasiones en la media de la década, una estética doble de la dominación: la primera, inspirada en la extrema derecha, por las implicaciones epidérmicas descritas en cuanto a cuestiones como el atrezo, y una segunda, estimulada a un nivel más profundo y deudora de la extrema izquierda, que opera como contrapunto anímico en torno a lo prohibitivo para echar ración doble de leña al fuego de la excitación y, desde luego, para cerrar el círculo artístico de Michael Ninn, cuya mixtura de fórmulas termina, ahora sí, acotando, para la pantalla, su exclusivo concepto de morbo.

\section{Totalitarismo y referencias en la bilogía}

Como quiera que resultaría estéril buscar esencias solo en el exhibicionismo reiterativo de los minutos puramente coitales, vale la pena sondear Latex y Shock en otros dos planos enunciativos, como mínimo igual de sugerentes: uno, derivado del fondo psicológico particular extraíble del guion y los diálogos en ambas películas, y otro, aplicable a la escenografía y el diseño de producción. Ambos se manifiestan influidos, indisimuladamente, por el conocido y celebrado universo del Orwell de 1984 (y aun por su novela precursora, Nosotros, de Evgueni Zamiátin), por cuanto es posible rastrear, en algunos de sus pasajes, las equivalencias declamadas en los dos filmes respecto al control de la actividad sexual por figuras absolutistas; el Gran Hermano, en el primer caso, y el Bienhechor en el segundo. Sobre el Estado, y sobre el individuo, planteaba el autor británico, a través de su protagonista, Winston Smith, lo siguiente:

El enemigo no era tanto el amor como el erotismo, dentro del matrimonio y fuera de él (...).Y lo que él quería, aún más que ser amado, era derruir aquel muro de estupidez aunque fuera una sola vez en su vida (...). El acto sexual, bien realizado, era una rebeldía. El deseo era un crimental (Orwell, 1980, p. $89)$. 
Por su parte, en el texto del ruso Zamiátin, las reflexiones sobre el pasado pre-dictatorial en que se asienta su distopía adoptan este cariz respecto al sexo:

¿Acaso no es un absurdo que el Estado (iosaba llamarse Estado!) pudiese tolerar la vida sexual sin control alguno? Cualquiera que le viniera en gana, cuando y cuanto quisiera... Era algo absolutamente acientífico, como las fieras (Zamiátin, 2008, p. 46).

Igualmente, la voluntad de Mangrove y del personal del psiquiátrico en que se halla Malcolm Stevens pasa, como en 1984, no por eliminar físicamente al elemento discordante, sino por reformarlo, al tiempo que Stevens muestra, en sus diálogos, una disposición a derrumbar los espesos muros de moralidad que le rodean, pese a reconocer que nunca deseó el extraño don que se le ha concedido, y que por ello se considera, en cierta manera, un hombre maldito.

De hecho, de los segmentos dialógicos de ambas cintas se deduce que el poder de Stevens podría quedar, acaso, en una mera habilidad de mentalista si no se hubiera destapado en una sociedad articulada sobre conceptos graníticos en torno a la culpa y la vergüenza, contra los que el personaje se rebela abiertamente. Inspirado, sin duda, por la ordenación metódica de la perversión que caracterizaba los textos de Sade, Ninn remite maniqueamente a la obliteración de la naturaleza humana vista en Saló o los 120 días de Sodoma (Salò o le 120 giornate di Sodoma, Pier Paolo Pasolini, 1975), cuando mira a la sociedad, y a las inconfundibles tesis del Marqués cuando aboga por la disipación moral del individuo y la demolición -cuanto más ruidosa, mejor- de los tabúes sexuales. Reza un pasaje de Juliette y las prosperidades del vicio:

La puta es la hija querida de la naturaleza, la muchacha buena es su execración (...). ¿Y qué ultraje más duro puede hacer una muchacha a la naturaleza que conservar como pura pérdida, y a pesar de todos los peligros que puede tener para ella, una virginidad quimérica cuyo único valor consiste en el prejuicio más absurdo y más imbécil? (Sade, p. 49). 
Por lo que atañe a la sección escenográfica, las referencias cinéfilas en la representación -siempre digital- de los exteriores se conjuran mediante rascacielos nocturnos, funcionales e impenetrables que mentan, ora a la creación videoartística, ora a la Gotham de Tim Burton en Batman (1989), ora -como se aprecia sobre todo en Shock- a Blade Runner (Ridley Scott, 1981), ora a la Bauhaus alemana y, sobre todo, a la seminal Metrópolis (Metropolis, Fritz Lang, 1927), algunas de cuyas escenas más famosas llegamos a ver proyectadas, incluso, en diversos monitores durante los dos metrajes. La génesis de esta concepción del espacio urbano empatiza manifiestamente, además, con lo expuesto por Cortés, cuando recuerda la influencia capital de la Ilustración a la hora de concebir y pensar una ciudad basada en la férrea separación de lo público y lo privado, en el aumento de su peculiaridad como espacio vigilado y vigilable, y, en suma, en el panoptismo y la estructura reticular de edificaciones como las cárceles:

Se trataba, por tanto, de crear espacios sin obstrucciones, volúmenes asépticos y puros donde los cuerpos son sometidos a la restricción de la soledad y a la falta de contacto con los otros. Con ello se hurta al cuerpo de cualquier tipo de sensación y sentimiento, de dolor o de impureza; y con la pretensión de hacerlo disciplinado, sólido y fuerte, se deshumaniza para acentuar su pequeñez en un espacio infinito, al tiempo que se racionaliza para negar el lenguaje del cuerpo y evitar cualquier tipo de acción no controlada o referencia de carácter sexual (Cortés, 2010, p. 50).

Tal vez por esta razón sobrevuela además, especialmente en Shock, un franco homenaje combinatorio a la anarquía moral que, durante la década de los 30, convirtió Berlín en una Babilonia alegórica de su inminente destino donde, como se recordará, la fe en el mundo anterior a la Gran Guerra, basada en certidumbres y reglas de autoridad, había capitulado también en el plano sexual, desaguando en una decadencia generalizada cuyo endiablado atractivo han inmortalizado, desde entonces, películas como Cabaret (Bob Fosse, 1972), estrellas del rock como Marilyn Manson (en el videoclip mObscene, Marilyn Manson, Thomas Kloss, 2003), o series de televisión 
como American Horror Story:Freak Show (Ryan Murphy, Brad Falchuk, 2014-2015). Sobre esta época reflexiona Blom:

Ahora, cuando el núcleo duro de la moral oficial se partió en dos, la vida se afirmó a sí misma, no en los bulevares y plazas (...), sino en apartamentos privados y habitaciones de hotel anónimas (...). Su influencia llegó desde los ingeniosos equívocos en las letras cantadas en cientos de miles de discos (...) hasta unos bajos fondos casi oficiales y, luego, hasta un submundo de prostitución realmente clandestino que satisfacía todos los gustos, todas las fantasías y todas las perversiones (Blom, 2016, p. 325).

En interiores, el espectáculo de Ninn no es menos desalentador: generadas igualmente por ordenador, abundan las salas asépticas de manicomio impregnadas de un molesto gris metálico que todo lo contagia; también los ambientes quirúrgicos, o altamente tecnificados, repletos de neones o pantallas con interferencias permanentes, o con imágenes de los actores observándose a sí mismos o a los demás mientras practican sexo. Escenas que superponen color y blanco y negro, o voces humanas que parecen rebotar siempre en las paredes de estancias fortificadas; cosificación extrema de las figuras mediante máscaras y/o trajes de látex; uniformes seminazis, extraños aditamentos producto de los onirismos más oscuros del alma... Va tocando, como vemos, un repaso urgente y ordenado de las dos películas, para ser más exactos a la hora de aprehender, al margen ya, de justificaciones teóricas, el abigarrado léxico con que Ninn juega a retorcer la mente del espectador mediante los cuerpos de sus personajes.

\section{Latex: armónico viaje a la locura}

Latex comienza con Stevens recluido en una celda, vigilado por los doctores que le tratan, y que entienden que sufre una suerte de alucinaciones agresivas, entre ellos uno apellidado Fish (Mike Horner). Alternando planos en blanco y negro y en color, el protagonista no tarda en introducirnos en la historia: "Sé que estáis ahí fuera, que me estáis observando -le espeta a las pantallas-. Mi crimen ha sido compartir con vosotros mis visiones. La 
verdad. Y por eso he sido juzgado (...). Aun así, no podéis mentirme. No podéis esconder vuestros pensamientos". Vemos la imagen desplazarse de la celda del reo hacia el exterior de la ciudad, a través de su ventana y, entre pantallas que lo dominan todo, y en las que se proyectan discursos del Líder y escenas de Metrópolis, la emisión de lo que sucede en su celda desemboca en una casa particular, donde se nos presenta una fantasía housewife típica, protagonizada por Sunset Thomas.

La siguiente escena, de corte onírico, muestra a Stevens en un coche de alta gama con otra versión de Thomas, a quien los créditos reconocen con el nombre de Kato porque, desde este momento, aparece vestida con un remedo sado del atuendo del famoso chófer que encarnara Bruce Lee en la serie The Green Hornet. El primero de varios interludios a caballo entre el videoarte y el videoclip superpone a continuación imágenes del protagonista delante de unas llamaradas, con cuatro reproducciones de la misma modelo (Emerald Estrada), vestida de pony girl con lencería de cuero y cadenas, flanqueándolo, y un muro metálico al fondo en el que puede leerse We see all (Lo vemos todo, F.1).

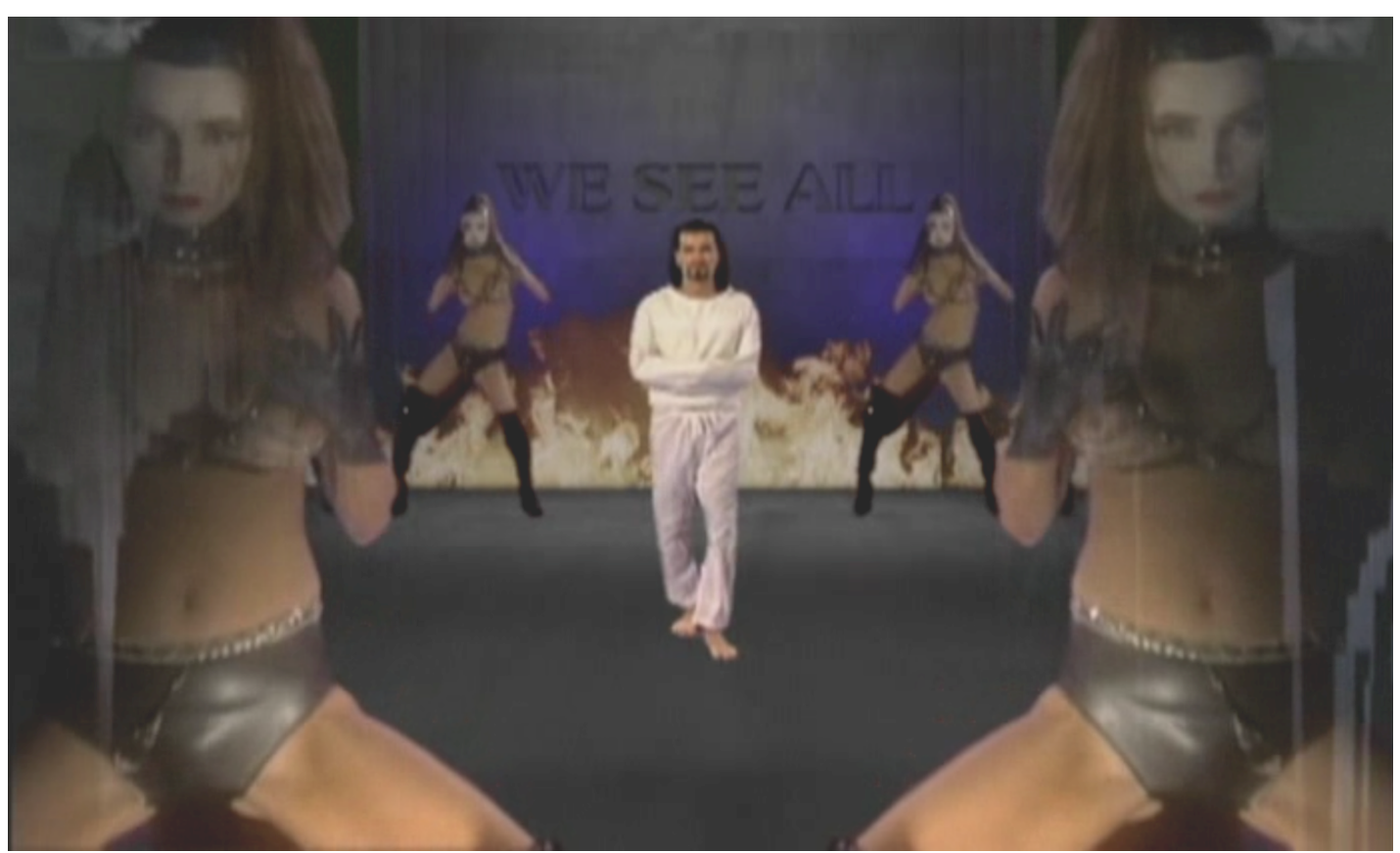

F.1: Lo vemos todo, o el individuo contra el sistema. (Captura de pantalla). 
De vuelta al hilo argumental, una voz en off indaga en el historial de Stevens describiéndolo como un "huérfano", "no criado en el ambiente de un núcleo familiar”. En una sala de terapia, frente a la doctora Mangrove, Stevens mantiene con ella una confrontación dialéctica en la que la especialista insiste en saber qué ve cuando tiene "esas alucinaciones”. "Todo el mundo tiene secretos, especialmente en lo que atañe al sexo. Y cuanto más tiempo los retienes, más duros se vuelven. Sin la culpa estaría ciego, pero siempre hay culpa, y siempre hay vergüenza”, explica. Malcolm termina tocando la muñeca de Mangrove en un arrebato de la discusión, y entonces contemplamos la fantasía de la doctora con su asistente (Sam Cooper), precedido por un revelador plano de la actriz en el que un lento travelling recorre poco a poco la distancia de la larga mesa de terapias, acercándonos a ella, que se muestra de pie y tranquila, aunque embutida ahora en el mismo atrezo de charoles negros y cadenas que ya nos es reconocible (F.2).

Resulta interesante cómo las escenas netamente sexuales buscan un alicatado de elevado concepto, al margen del exhibicionismo clásico, acusando un muy elaborado montaje de videoclip que relaciona el cumplimiento de las fantasías de los personajes con los espejismos quiméricos del citado formato cuando ajustan, por ejemplo, el ritmo de las imágenes a la velocidad que dicta la percusión electrónica de la música de fondo. Tras la escena con Mangrove, paradigmática en este proceder, regresamos a los interludios oníricos, de los cuales Kato pasará a partir de ahora a ser musa indiscutible, mostrándose de nuevo en escenarios oscuros y repletos de pantallas, sobre cuyas imágenes la voz en off continúa dando detalles del caso de Stevens. Posteriormente, se materializan unas fantasías lésbicas y una suplantación de cuerpo inducida al recubrir de látex el cuerpo de Malcolm, toda vez que este material neutraliza su poder, siendo, además, el protagonista, incapaz de proyectarse a sí mismo en sus propias fantasías. 


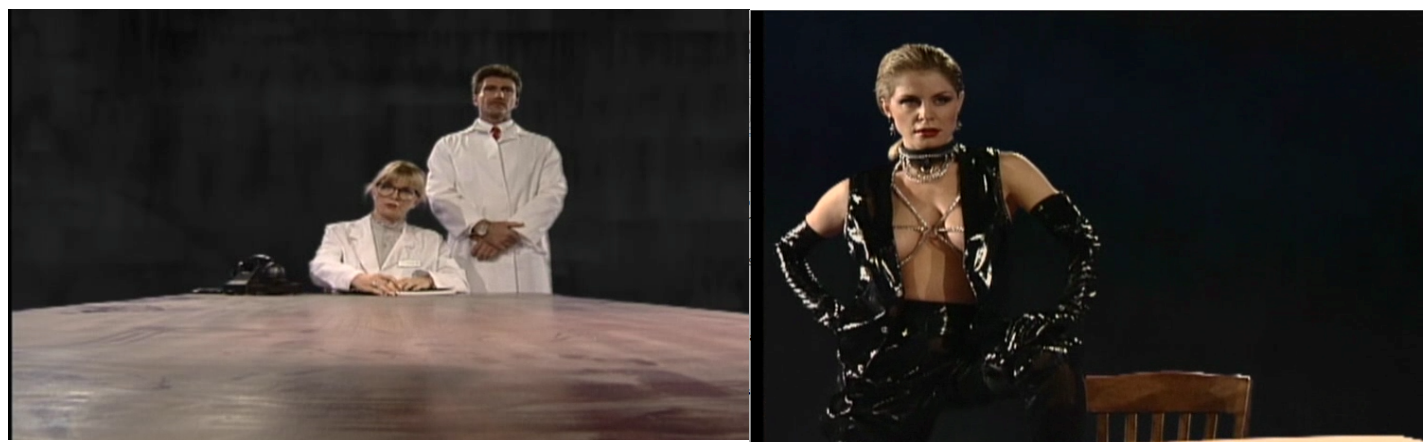

F.2: Lillian Mangrove. La distancia como superficie de la moralidad vs. la cercanía liberadora de la fantasía. Captura de pantalla.

En la siguiente escena, vemos a Kato y a Stevens aparcar el coche ante los estudios del programa televisivo Julie, the Show. Durante la entrevista, realizada en un estudio con la misma ambientación negra y metálica que rodea el resto de los escenarios, Stevens relata la primera manifestación de su poder (que experimentó a los cuatro años), y también su frustrada relación de pareja con Gwen (Jeanna Fine). Julie le reta entonces a hacer un experimento en directo con ella, amparándose en su trabajo como periodista de investigación, y al poco asistimos a la fantasía de la presentadora, materalizando sobre el mismo plató un trío con dos técnicos del estudio (Cal Jammer y Tom Byron), aunque cambiando el fondo "real" por otro vacío, de un rotundo rosa eléctrico (F.3).

En la siguiente escena, volvemos al escenario inicial de la casa particular. Malcolm le cuenta a Kato retazos de su historia. Este es el único instante en que asistimos a la verdadera intimidad de Stevens, resultando Kato aquí como su única proyección propia; una amiga imaginaria a la que revelarle, por fin, que "la libertad es un estado mental" que nada tiene que ver muros, fronteras o regulaciones. "Aquellos que se liberan completamente son los únicos en los que nada tengo que encontrar. Eres la única en la que puedo confiar. Tú no albergas culpa, ni dolor”, le dice, antes de entregarse a ella.

La última secuencia, "El juicio de Stevens desde el Hampshire Hall” (F.4), muestra de nuevo un plano digital de elevados rascacielos sin ventanas, con pantallas salpicadas de escenas de Metrópolis. El Líder, uniformado con un 
sencillo atuendo de ecos fascistas, se dirige a unas masas enfervorecidas, recreadas digitalmente, que agitan el puño ante una megapantalla. Se refiere a Stevens como un intruso que, con sus revelaciones, ha violado "todo aquello que debe permanecer oculto". Entonces se condena al reo a ser sacrificado "por el bien de la colectividad” (tras habérsele puesto, una vez más, el traje de látex), observando a Gwen copular con dos hombres ataviados con corazas (el Líder también observa). Pero, mientras esto sucede, en un conglomerado de escenas paralelas deliberadamente confusas, Kato aparece para liberarlo, se entiende que mentalmente, dado que el particular instante se restringe al blanco y negro, y además el personaje no lleva el látex cuando se levanta y abandona su trono de castigo.

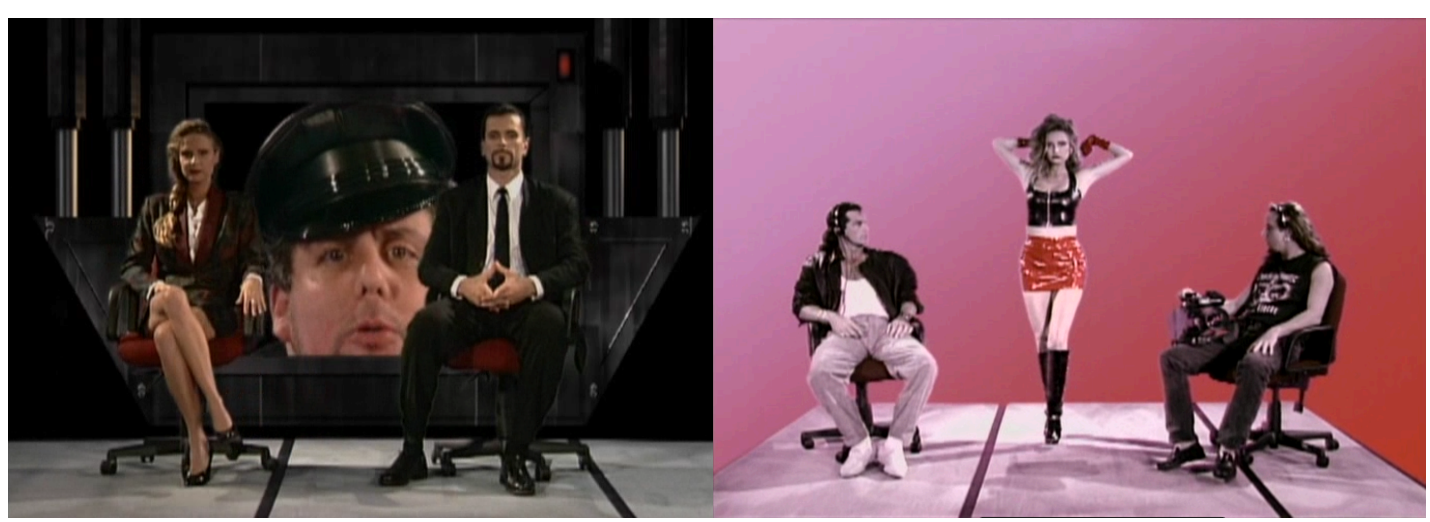

F.3: La fantasía libera a Julie de la complicada atmósfera de su trabajo, aunque no de introducir en ella a dos de sus subalternos. Captura de pantalla.

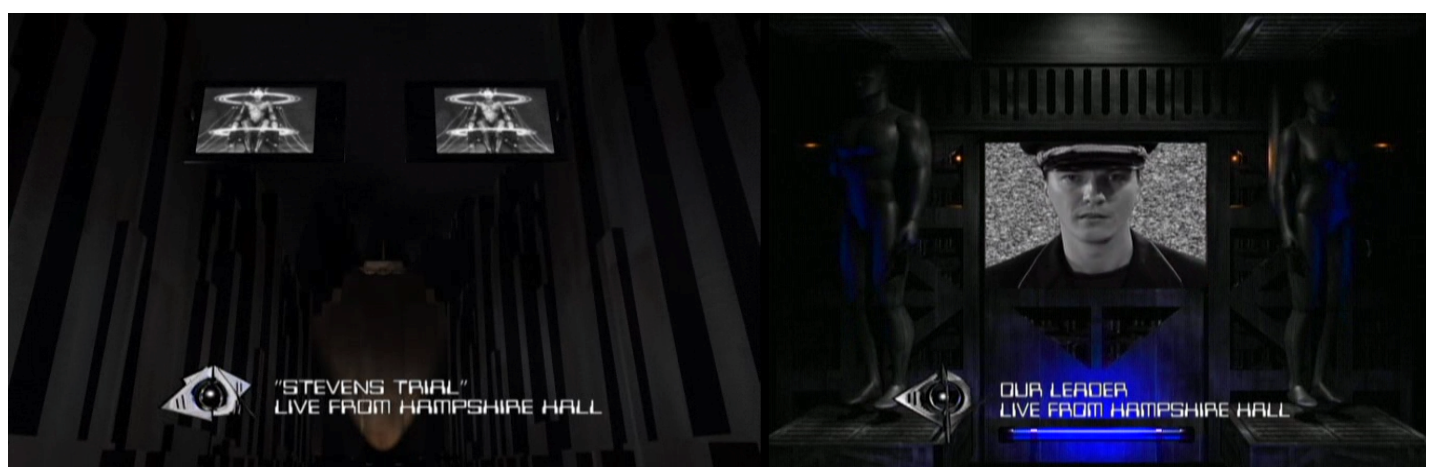

F.4: El juicio de Stevens, con escenas de Metropolis, y el alegato del Gran Hermano (Nuestro Líder). Captura de pantalla. 
La película termina donde comenzó: en el área de monitorización de pacientes del sanatorio, donde, de algún modo, se han intercambiado los papeles: el doctor Fish está ahora en la celda, en el lugar de Stevens, mientras éste escapa junto a Kato en el modesto automóvil del doctor, transformado repentinamente -mediante la técnica del morphing- en el coche de alta gama que ya conocemos. ¿Ha vencido Stevens al sistema gracias a sus habilidades mentales, o fue Fish quien estuvo siempre confinado, inventándose un personaje revolucionario que nunca existió?

\section{Shock: regreso a la Matrix del porno}

Ha escrito Meléndez:

Michael Ninn's remarkable Shock provides another ideal example since it is, in many ways, an attempt to broaden the possibilities of high-end, straight pornography produced on the industry's equivalent of a Cecil B. DeMille budget (...). In an effort to convey sexual ecstasy, Shock experiments not only with extravagant content details like costumes and mise-en-scène but more radically with the very workings of the video médium" (Meléndez, 2004, p. 406).

Por esta razón, y también por desarrollarse casi enteramente dentro de la mente desquiciada de un Stevens dueño y señor, aquí, de su propio universo virtual, Shock resulta tal vez más abstracta y menos política en su planteamiento, aunque permanecen en ella los principales oropeles estéticos sobre el oscurantismo y la dominación oficiados en Latex. Esta vez, es Lillian Mangrove la que aparece al principio ingresada, en estado catatónico, escena a la que sigue otra muy trabajada en los términos técnicos que indica el autor antedicho, con una Jeanna Fine en claro trasunto de Marilyn Monroe, mostrándose en blanco y negro dentro de una escena coloreada de la que participan activamente un hombre anónimo, y el propio Stevens.

La doctora Hellstrom (Ona Zee), al mando ahora en la sección del Psiquiátrico, discute con el doctor Emerson (Mickey Alexander) sobre las bondades del tratamiento de electroshock en pacientes con habilidades 
psíquicas. El doctor Ross (George Kaplan) incide en el caso de Mangrove, estableciendo aquí el principal eje conectivo del libreto respecto a su predecesora: "Su mente era brillante hasta que se entrevistó con este paciente”, dice, refiriéndose a Stevens, quien se halla igualmente catatónico frente a ellos en una camilla. El tratamiento, de un voltaje mayor al permitido, logra que Stevens despierte momentáneamente, pero éste sujeta entonces a la enfermera Gwen (Shayla LaVeaux), quien se siente caer desde una gran altura, en su tránsito al reino psicosexual de Stevens, para recobrar la conciencia en una azotea de ambiente expresionista (F.6), donde es poseída por dos gárgolas de piedra (T.T. Boy y Vince Vouyer).

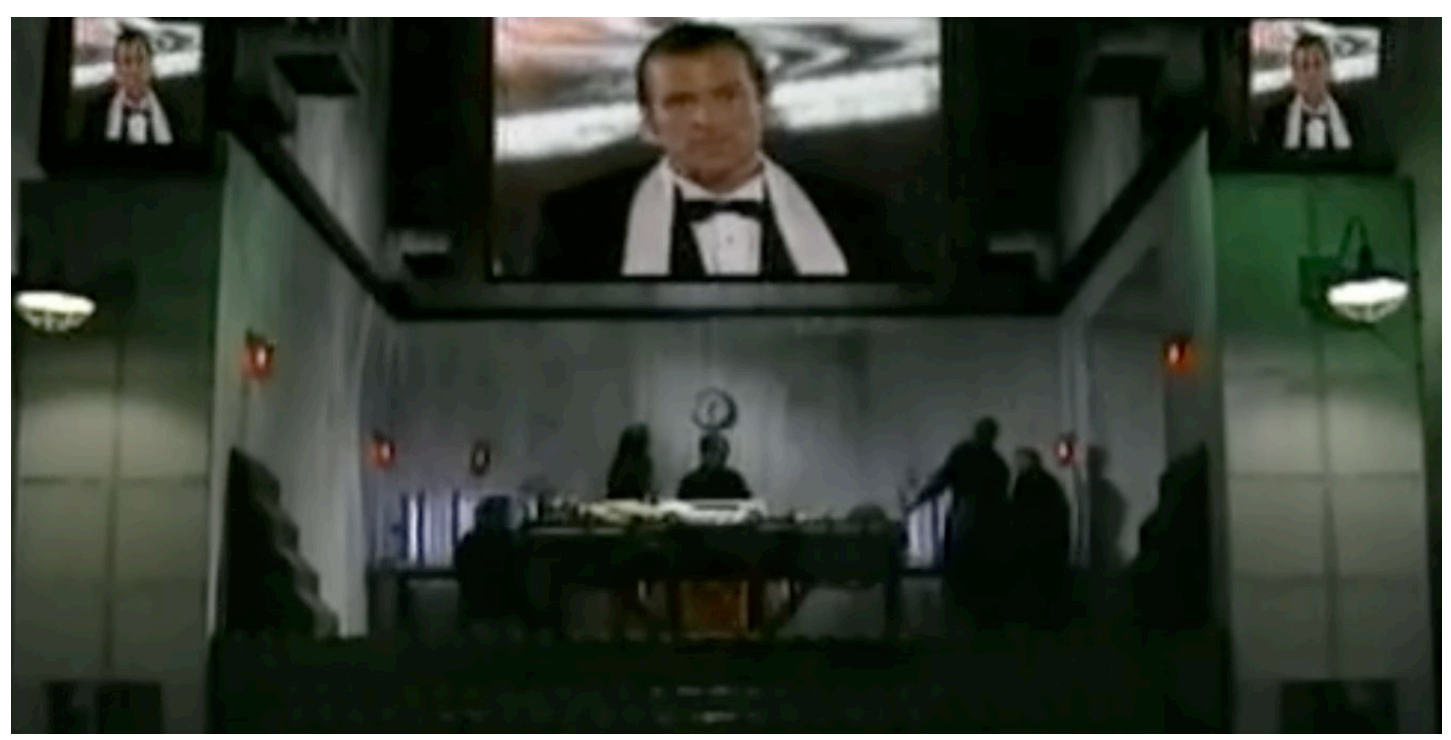

F.5. En Shock, Stevens es ahora el líder del sistema. (Captura de pantalla).

De vuelta al sanatorio, el semidiós aparece en todas las pantallas (F.5): su poder mental, que se ha convertido en una entidad libre y autónoma, le ha transformado en el dueño absoluto del sistema, pese a que su cuerpo sigue inerte en la camilla. Exige a Hellstrom que le declare legalmente sano, so pena de dejar en coma a Gwen, a quien controla tras haber quedado también catatónica tras ser víctima de su "toque" en el mundo real. 


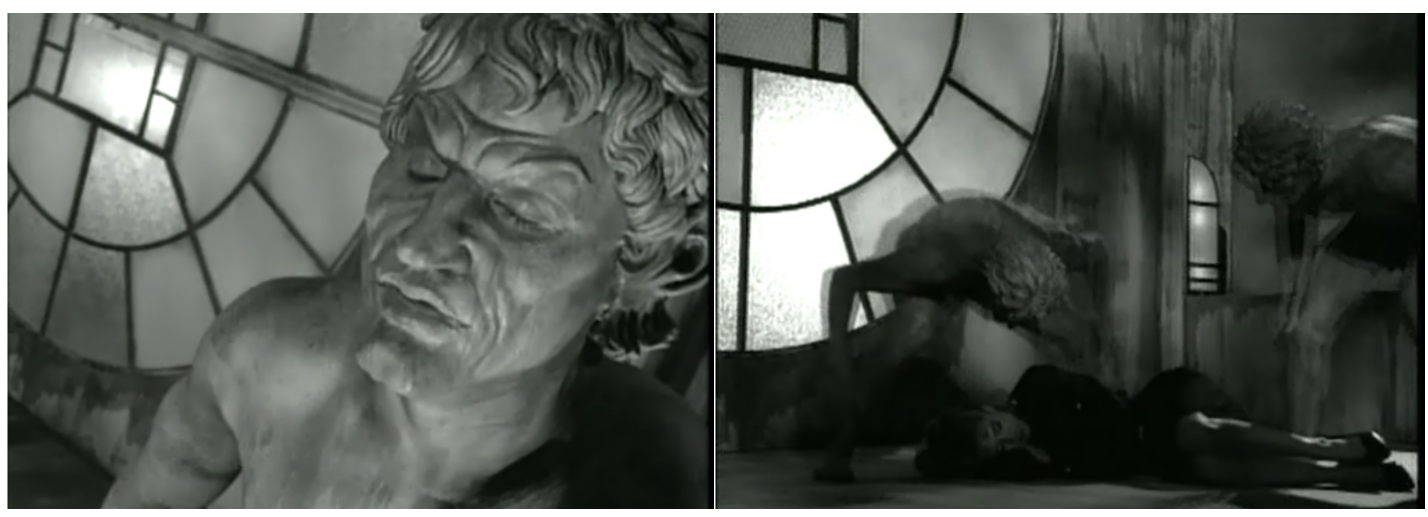

F.6. Expresionismo en las formas: blanco y negro, dos gárgolas de piedra y un fondo art déco, alimentan la fantasía original de Gwen. Captura de pantalla.

Hellstrom llama entonces a Mangrove, quien en lo que parece un salto temporal aparece sana y ataviada en cuero negro, sin nada que recuerde a la recatada doctora de la primera parte. Existe aquí un primer puente tendido a Blade Runner, que se confirmará en los minutos siguientes: la doctora anuncia que su nuevo trabajo puede describirse como "terapia de choque", y que es la única persona autorizada para ello por el Gobierno, lo que recuerda al eufemístico "retiro" con que se calificaba la eliminación de los replicantes, en el clásico de ciencia-ficción, y que aquí cabe identificar con los elementos disidentes del sistema. A cambio de readmitir a Mangrove en su antiguo puesto, ésta atraviesa una Puerta de la Mente hacia el mundo de Stevens, junto con sus dos guardaespaldas (Peter North y John Decker), con el objetivo de derrotarlo y de traer de vuelta a Gwen.

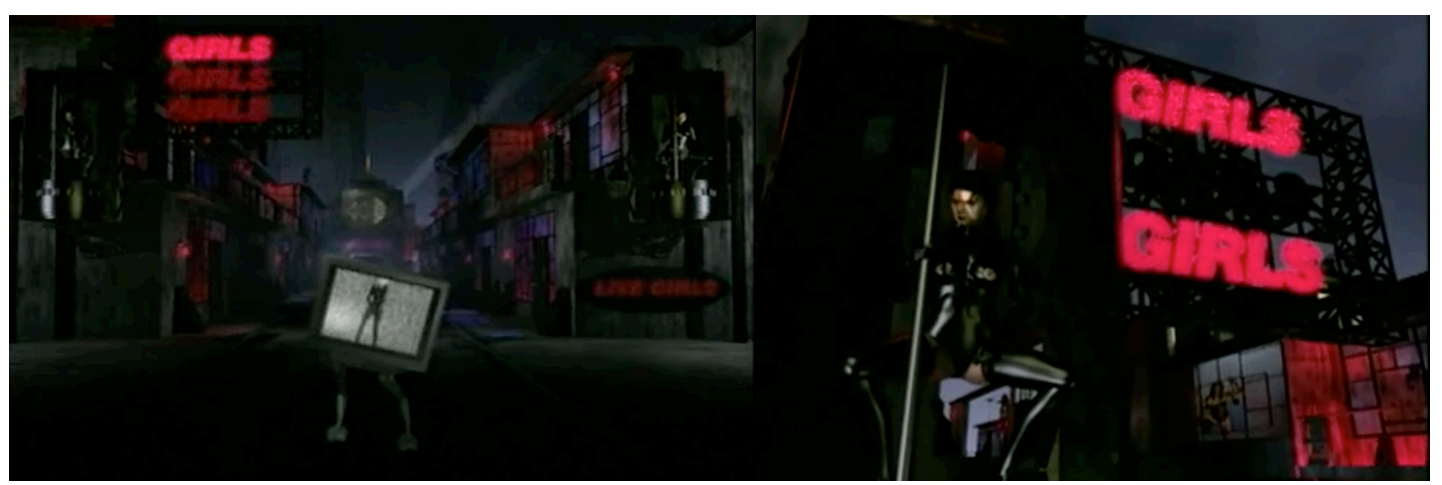

F.7. En el "mundo libre" de Stevens, los televisores caminan y la ambientación apela a Blade Runner. Captura de pantalla. 
En este "mundo libre", la sensación de duermevela y de dulce confusión es constante, aunque, como vemos, su teórico libre albedrío entra en paradoja con el sustrato estético de las fantasías predominantes: colateralmente a una ensoñación inicial de Mangrove con sus dos adláteres, el protagonista ha presenciado otra escena de sugerencias lésbicas entre cuatro mujeres vestidas de criadas, que desemboca finalmente en sexo entre dos chicas ataviadas, peinadas e insertas dentro de un entorno claramente deudor, no tanto de la Berlín en decadencia descrita en párrafos anteriores, como del modo en que el cine clásico ha venido reflejándola a través de su historia. A la decrepitud en que la iluminación sume los elegantes decorados, hay que agregar, además, escenas simuladas de dominación y sadomasoquismo entre las chicas, en el tramo final de la escena.

Restablecido el equilibrio mental de Mangrove, el trío comprueba hasta qué punto el orden de ese cosmos virtual se contrapone a las restricciones absolutistas del real: abundan los locales de prostitución; una televisión camina hacia ellos con escenas de Kato, y, sobre una cornisa, una hooker realizada en CGI incita con su baile (F.7). La siguiente escena, que implica a un grupo de prostitutas, sirve para presentar a un extraño y orondo personaje, D. Bock (Simon Delo), quien con aspecto similar a un luchador de sumo mantiene atada, como mascota ("Puppy” en los créditos), a la actriz Tricia Yen, mientras el equipo de Mangrove avanza por el suburbio. Entretanto, Gwen, con un elegante vestido dorado, viaja con Kato en el coche de Stevens en un onirismo sobre la integración de la ayudante en el nuevo mundo, sorteando calles en las que, de nuevo, las pantallas mezclan referencias de Metrópolis con otras a Latex, en un conjunto oscuro, autorreferencial y cyberpunk. Stevens entra en un elegante club del brazo de las dos mujeres, a medio camino entre un auditorio y, de nuevo, un cabaret berlinés. En él, Dino Ninn, hermano del director y compositor de la música de la cinta, aparece dirigiendo a una orquesta, que toca un tema solemne con coros de soul, en una escena decidida a tocar el techo del glamour, y del equilibrio de sensaciones visuales, dentro de la bilogía. "Solo vemos lo que 
queremos ver. Cuando abramos los ojos, veremos la noche convirtiéndose en luz del día. Lo veremos”, recita Stevens, erigido en maestro de ceremonias.

Mangrove exige a D.Bock (para ella una parte de Stevens) que le entregue a Gwen, y éste pide a cambio "lo que siempre hemos querido: libertad". Más tarde, Stevens y Gwen aparecen sentados en un sofá, desde el que Malcolm entregará a la chica a un ritual para evitarle "el dolor del regreso". Aparecen entonces cuatro pony girls, capitaneadas por Kato, quien sustituye a Gwen en el sofá. Las cinco chicas organizan una orgía en la que Stevens reparte unos consoladores metálicos, que recuerdan a puñales, y que Kato sirve en una bandeja de plata como talismanes del citado ritual. Hacia el final de la escena, también se produce una fantasía de dominación: una de las pony girls, ensillada, sirve de montura a una amordazada Gwen, quien acabará cubierta por una lluvia de semen falso, procedente de los strap-ons que porta el resto de las chicas. Tras esto, y vestida ahora con atuendo felino, Gwen tiene una escena con Stevens para completar la extraña liturgia.

$\mathrm{Al}$ poco, asistimos al duelo final. Stevens está desnudo, sentado frente a un escenario metálico que nos resulta familiar, y sujeta una paloma en clara referencia al epílogo de Blade Runner. Asegura que ha devuelto a Gwen, y, ante las amenazas de los guardaespaldas, también los hace desaparecer sin pestañear. “¿Crees que a ellos les preocupas si vuelves o no?”, pregunta entonces a Mangrove, quien comprende que su acuerdo con Hellstrom era solo humo. "No me importa cómo llegué aquí. Lo único que me importa es regresar”, grita entonces, a lo que Stevens, liberando la paloma a cámara lenta -como Roy Batty (Rutger Hauer) hiciera en el filme antedicho-, espeta finalmente, en un sorpresivo giro: “¿Y crees que alguna vez te fuiste?”. Mangrove siempre estuvo catatónica en su celda (lo que también recuerda a la orwelliana Brazil -Terry Gilliam, 1985), y Stevens siempre fue su alter ego, por fin eliminado, al parecer, y según anuncia una voz en off, gracias a la terapia de electroshock combinada con medicación antipsicótica. La pantalla de su celda, en el último plano del filme, se apaga para siempre, y con ella toda esperanza de escapar del sistema. 


\section{Conclusiones}

Concebidas como universos autónomos dentro del género, aunque interconectados entre sí, Latex y Shock no solo se sitúan temporalmente en la frontera previa a los cambios forzados por la ocupación digital, sino que parecen intuir el auge del desprecio por la preproducción, y su generalizado envite reduccionista, inmolándose sin saberlo en un altar artístico que, como el tiempo ha deparado, resulta crucialmente apto para medir y separar ambas eras. Salvo por casos muy aislados como la monumental Fashionistas (John Stagliano, 2002), ello no obsta para que la parte de la industria interesada en editar filmes de alto presupuesto haya seguido produciendo obras reconocidas por crítica y público, casi siempre en la estela paródica de antaño y magníficamente ambientadas, como Pirates (Joone, 2005) o Star Wars XXX. A porn parody (Axel Braun, 2012), pero muy lejos, ya, del concreto vuelo rupturista sentado por autores como Ninn durante los años 90.

Jugando, pues, con las tesis distópicas de Orwell (antes de que el mundo virase decididamente, más bien, hacia las predichas por Huxley), y apelando a la cultura previa del espectador, la estética específica del totalitarismo descrita en los párrafos iniciales, que Ninn solemniza como fuente argumental y visual aunando placeres distintos, innova y discurre generalizadamente por ambas películas, si bien en Shock se rebaja, como hemos dicho, el tono político inicial, potenciando el concepto en la inmediatez de los atuendos y/o haciendo más explícitas, en un sentido más preceptivo, y más reconocible en las acciones, las escenas de sumisión. En la misma órbita, no debe sernos ajena, tampoco, la paradoja que puede observarse en el hecho de que, si bien en Latex existe un Gran Hermano que condiciona a la sociedad en que surge el libertino/libertario, en Shock es este último quien ejerce, no ya como líder absolutista dentro de su propio entorno, sino como un dios elemental por quien todas las criaturas que habitan en su espacio respiran y actúan, cuando no se trata de sus proyecciones directas. Incluso es posible, a tenor de las codas de ambas películas, que los ideales de autonomía total representados por el protagonista no sean más que un anhelo de aquellos cuya mente ha 
sucumbido a la opresión. En los dos clímax, además, se suceden rituales con obvias connotaciones de castigo que sitúan, una vez más desde una perspectiva sádica, el punto de inflexión para la liberación mental y moral -y a la postre de las ataduras del sistema- de los personajes de Stevens y Gwen.

Las deliberadas interferencias, en fin, que en la transmisión convencional del acto físico maneja Ninn mediante técnicas y tecnologías asociadas a formatos ajenos al habitual, logran pergeñar una paradoja última mediante la cual su porno se sitúa más que nunca en la esfera íntima, toda vez que abre la puerta a un abanico de sensaciones poliédricas relacionadas, más allá de lo meramente esperable, con el placer visual y auditivo extradiegético. Ciertamente, hoy se aprecia lo alambicado de algunos recursos del director, pero queda para la posteridad su talento aplicado, del que no dejó de hacer gala en su filmografía posterior.

\section{Referencias bibliográficas}

Blom, P. (2016). La fractura. Vida y cultura en Occidente, 1918-1938. Barcelona: Anagrama.

Corazón, A. (2013). La vida sexual en la Unión Soviética. Recuperado de: http://www.jotdown.es/2013/o7/la-vida-sexual-en-la-union-sovietica

Cortés, J.M. (2010). La Ciudad Cautiva. Control y vigilancia en el espacio urbano. Madrid: Akal.

Foster Wallace, D. (2009): Hablemos de langostas. Barcelona: Debolsillo.

Gonzáles, J.D. (2012). Cuerpo y obscenidad en los medios: un acercamiento estético a la mediación intersubjetiva de la pornografía. Tesis presentada para optar al título de Magister en Estética. Recuperado de: http://www.bdigital.unal.edu.co/9159/1/71365712.2012.pdf

Hernández, C., Crespo, M. (2013). Apuntes sobre una sociología del porno. Apuntes de investigación del CECYP. Recuperado de: http://www.scielo.org.ar/scielo.php?script=sci_arttext\&pid=S185198142013000200002

Meléndez, F., en VV.AA. (2004). Porn studies. Durham: Duke University Press.

Orwell, G. (1980). 1984. Recuperado de: https://blog.smaldone.com.ar/pdf/1984-bilingue.pdf

Pagés, N., Rubí, N. (2012). Eros Ausente: apuntes sobre la erotización del nazismo. Revista de Estudios sobre genocidio. Recuperado de 
http://revistagenocidio.com.ar/wp-content/uploads/2013/05/025-a048.pdf

Posada, S. (2017). El mejor crítico de cine porno se destapa. Entrevista a Lucas Soler. Recuperado de:

http://www.soho.co/historias/articulo/el-mejor-critico-de-cineporno-se-destapa/30867

Purcell, N. (2012). Violence and the pornographic imaginary. The politics of sex, gender and agression in harcore pornography. Routledge: Nueva York.

Ruiz-Tagle, J. (2013). Creatividad y estereotipia en el sadomasoquismo. Revista Nomadías. Recuperado de http://www.nomadias.uchile.cl/index.php/NO/article/viewFile/2994 $4 / 31723$

Sade, Marqués de (Sin Fecha). Juliette, o las prosperidades del vicio. Recuperado http://seronoser.free.fr/sade/1800\%20Juliette\%201.pdf

Sontag, S. (2011). Bajo el signo de Saturno. Barcelona: Debolsillo.

Zavala, I. (2014). La impudicia y lo obsceno en la cultura concemporánea. Errancia, revsita de Psicoanálisis, Teoría Crítica y Cultura. Recuperado de:

http://www.iztacala.unam.mx/errancia/v9/PDFS_1/TEXTO\%20LIT ORALES\%201\%20ERRANCIA\%209.pdf

Zamiatin, E. (2008). Nosotros. Madrid: Akal. 